\title{
Spatiotemporal Analysis of LANDSAT Satellite Imagery for Change Detection in Česma Forest Ecosystem
}

\author{
Ela VELA, Vanja MILJKOVIĆ*, Luka BABIĆ
}

\begin{abstract}
Development of remote sensing and increased availability of satellite imagery of different spatial, spectral, temporal and radiometric characteristics makes information obtained from such sources of vital importance for studying and mapping vegetation. Vegetation indices have a significant role in vegetation change detection and tracking, whether in quantity or quality terms. Each index has specific significance and performance characteristics. A multiple regression statistical analysis of average vegetation index values (NDVI, NDWI, GNDVI, EVI and SAVI) was performed for 2012, 2013 and 2014 periods of a wider Česma forest area near Vrbovec, Croatia. Further, rasters using three-year average values, sums, variances and standard deviations for all five indices were created. Differencing of average NDVI index values for years 2005 and 2014 was also performed. Imagery chosen was from the active vegetation period and used as a basis for cluster analysis detection of significant change areas. Česma forest area was selected due to previous field monitoring and point analysis conducted (2012, 2013 and 2014) that serve as validation for this research. Finally, a raster analysis of select areas, surrounding accumulation dam and encompassing Česma forest area exclusively, was conducted. The intention was determining vegetation index change dynamics. Spaciotemporal analysis around accumulation dams determined vegetation changes in dam areas. The advantage of the applied method is that, by using the Principal Components Analysis - PCA, it allows change detection, tracking and monitoring on wide areas more promptly than with other methods. The analysis itself was made using 92 LANDSAT images acquired over a 10-year period.
\end{abstract}

Keywords: geostatistics; LANDSAT; remote sensing; spatiotemporal analysis; vegetation index

\section{INTRODUCTION}

Remote sensing has a significant role in numerous diverse research fields. Its use is next to mandatory in environmental studies, hydrology, minerology, ecosystem studies and others [1]. Forestry application research was conducted to prove applicability of satellite imagery in assessing and monitoring natural resources, determining land use, tree types and development stages of forests, forest classifications, forest inventories, biomass assessments, monitoring forest conditions and determining changes, forest damage evaluations, early detection and monitoring forest fires, studies and condition assessments following natural events and disasters, wildlife and hunting applications, studying of protected areas and the like [2]. Data obtained from raster analysis were, along with the results of field research, integrated into a comprehensive spatiotemporal database as a basis for geostatistical analysis. This provides an increase in accuracy for change detection tracking in a forest ecosystem when combined with analysis from other relevant scientific areas, and finally results in determining impact on an entire forest ecosystem. Previous field research of the area includes ground water levels survey for 2012-2014 period, and a point raster analysis on 22 piezometer locations in a tenyear time span (more in [3]). A semiautomatic selection and download method of imagery for the 2005-2016 period was implemented using QGIS followed by manual removal of images containing cloud cover or those whose quality did not meet analysis requirements. A total of 92 images form Landsat 7 and Landsat 8 sensors was collected for a 10 year period and used in analysis.

This paper describes how the trends coincide with vegetation indices not atmospherically corrected, what, unlike previous researches, enables tracking changes on wider areas in real time. Prior investigations [3] were used to verify results obtained in this research.

\subsection{Research Area}

Economic unit "Česma" is located between longitudes $16^{\circ} 36^{\prime}$ and $16^{\circ} 49^{\prime}$ east and latitudes $45^{\circ} 49^{\prime}$ and $45^{\circ} 53^{\prime}$ north, covering an area of 3423.03 ha. It is positioned in a valley surrounded by mountains Papuk and Psunj east, Kalnik and Medvednica west, Moslavačka gora south and Bilogora north of the valley (Fig. 1).

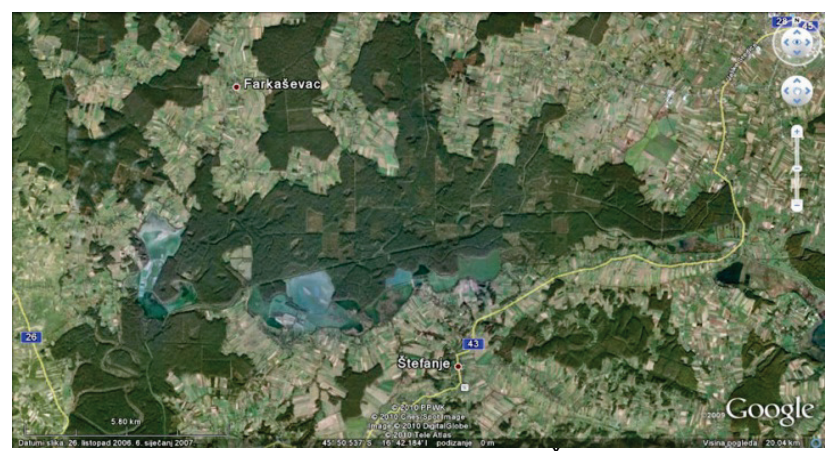

Figure 1 Satelite imagery of the research area - Cesma forest (Google)

The area was protected in 1982 as a special reserve of forest vegetation. Česma forest encompasses two forest sections. The natural differentiators of those sections are the forest communities of oak trees and hornbeam trees estimated to be 130 years old [4]. Such forest communities are extremely susceptible to climate fluctuations and, thus, to change.

Lowland Česma oak forest was chosen as a test filed due to its specific location of test accumulations dams (barriers placed in 2007 and 2009). The drainage canal network built alongside forest transit lines was connected to old waterways as the main recipients, which caused increased draining of surface waters from the forest, resulting in change of ecological conditions. This resulted in drying out the area, change in vegetation structure and decreased forest regeneration.

As a possible relief measure, foremost for the draught, building and placing dams in dried out watercourses was 
implemented to contain the water within the forest. To eliminate negative effects of the implemented measure, monitoring of seasonal tree growth, crop yield and leaf mass production was established in the accumulation areas [5]. Thus, a network of piezometric stations was established and ground water levels and regimes were monitored. Current analysis of piezometric measurements shows changes in ground water levels, which led to change manifested in the forest ecosystem [6].

\subsection{Data Collection and Methodology 1.2.1 LANDSAT}

Landsat 7 and Landsat 8 images were used in this research. Landsat ETM+ offers images in eight spectral ranges, wavelengths from $0.45 \mu \mathrm{m}$ up to $0.9 \mu \mathrm{m}$. Surface area covered by one image is around $179 \mathrm{~km}$ north-south and 183 east-west direction [7]. Resolution of all but the panchromatic channels is $30 \mathrm{~m}$. Panchromatic channel has a $15 \mathrm{~m}$ resolution and serves in spatial resolution improvement and detections.

Landsat 8 mission has scientific characteristics and, unlike its predecessor, has no operational mandate but an open and free access to data. The main goal of the mission is to maintain continuity of observation so that the data is consistent and comparable to previous Landsat implementations. Landsat OLI and TIRS images contain nine spectral ranges of $30 \mathrm{~m}$ resolution, with one channel (the eighth) having a $15 \mathrm{~m}$ resolution. The new channel 1 , of expressly blue spectrum, is used in coastal research, while the new channel 9 is used for cirrus cloud detection. Channels 10 and 11 provide higher accuracy of surface temperatures in $100 \mathrm{~m}$ resolution. The approximate scene size is $170 \mathrm{~km}$ north-south and 183 east-west direction acquired daily (550 per day on average) [8].

\subsubsection{Empirical Vegetation and Water Indices}

Both the empirical vegetation and water indices were used in raster analysis of Česma forest. Empirical vegetation indices encompass the $S R$ - simple ratio, $N D V I$ - Normalized Difference Vegetation Index, GNDVI Green Normalized Difference Vegetation Index, SAVI Soil-Adjusted Vegetation Index and EVI - Enhanced Vegetation Index. Empirical water indices encompass NDWI - Normalized Difference Water Index and MNDWI - Modified Normalized Difference Water Index.

Precision Leaf Area Index ( $L A I)$ surveys are vital to understanding biological and physical processes involving vegetation and are data used in ecosystem modelling [9]. $L A I$ is a nondimensional variable quantifying the leaf to ground surface ratio.

According to research, $S R$ and $L A I$ show the greatest correlation ratio. Its significance was proven in vegetation detection, where it reduces the atmospheric and topographic effects, but has a low ground, ice and water detection response. $S R$ is calculated using [10]:

$S R=\frac{R E D}{N I R}$

NDVI is the most commonly used indicator in vegetation cover change detection. It is often used as an indicator in tracking vegetation health and dynamics thus allowing spaciotemporal comparisons in vegetation [11]:

$N D V I=\frac{(N I R-R E D)}{(N I R+R E D)}$

GNDVI uses the green channel instead of the red one. It shows greater correlation to $L A I$ than $N D V I$ [12]:

$G N D V I=\frac{N I R-G R E E N}{N I R+G R E E N}$

SAVI is a modified NDVI. It is used in cases when it is necessary to remove the atmospheric and topographic effects in scarce vegetation cover areas [13]:

$$
S A V I=\frac{(1+L)(N I R-R E D)}{N I R+R E D+L}
$$

$E V I$ is also a modified $N D V I$ that has increased biomass sensitivity with minimal atmospheric reflection and ground surface effect. Thus, it is a valuable index for monitoring forest vegetation cover [14]:

$$
E V I=G \frac{N I R-R E D}{N I R+C_{1} \cdot R E D-C_{2} \cdot B L U+L}
$$

NDWI index was designed to accomplish the following effects: maximum water refraction using the green channel, minimization of low reflection in near-infrared $(N I R)$ spectral range off water bodies along with utilization of high vegetation and earthen objects reflection in the NIR spectral range. The formula for this index is [15]:

$$
N D W I=\frac{G R E E N-N I R}{G R E E N+N I R}
$$

$M N D W I$ reduces noise effects and improves clear water bodies delineation in imagery. $M N D W I$ is obtained using the following formula [13]:

$$
M N D W I=\frac{G R E E N-M I R}{G R E E N+M I R}
$$

where $M I R$ is the middle infrared spectral range.

\section{PROCESSING AND ANALYSIS OF RESEARCH RESULTS}

2.1 Raster Analysis of Vegetation Indices

This research used a multiple regression average value statistical analysis of vegetation indices for years 2012, 2013 and 2014. It is a type of average index values linear regression analysis using each 2012 raster as a nonindependent variable and corresponding 2013 and 2014 rasters as independent (predictor or regression) variables. A new raster based on the regression was derived. The initial assumption for using this analysis was linear variable correlation. The analysis was made for the stated 
period as it corresponds to the period of piezometer observations. Thus, analysis trends could be compared to in-field conditions and interaction between groundwater and treetop appearance could be determined.

A statistical analysis based on average vegetation indices was made for the 2012-2014 period.

Three-year average value, sums, variances and standard deviations rasters for all five indices were derived. NDVI average value minimum and maximum values are 0.3-0.61, sums 0.34-1.85, variance 0-0.004 and standard deviations $-0.013-0.059$ (Fig. 2). Vegetation index standard deviation is a value that statistically quantifies the variance and shows the deviation of data from the average. Unlike variance it uses the same units as the data itself. This analysis considers the wider Česma forest area, which affects the average values of the rasters and the results. Hence, subsequent analysis involved the forest area exclusively.

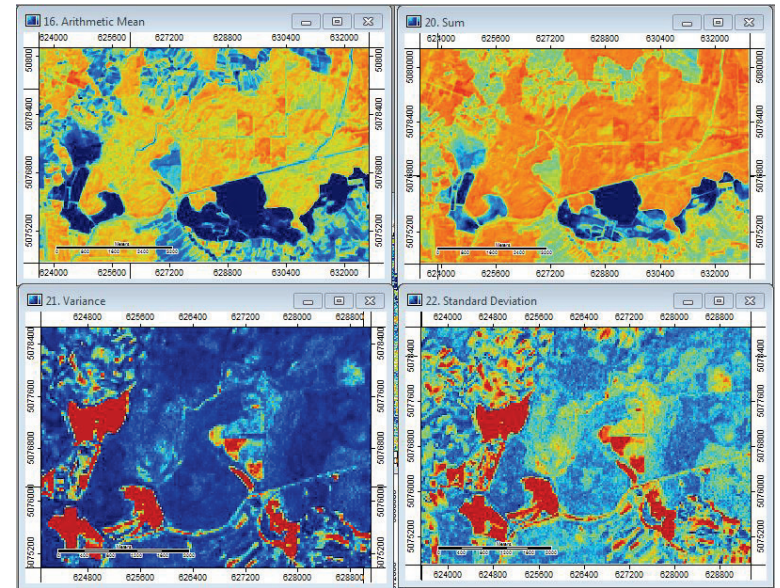

Figure 2 Statistical analysis of NDVI average values for years 2012, 2013 and 2014 of a wider Česma forest area [16]

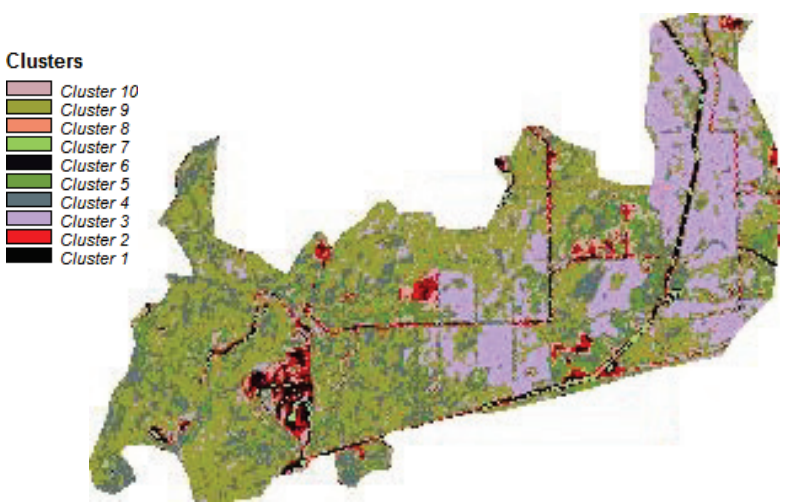

Figure 3 Cluster analysis of NDVI differences of years 2005 and 2014 [16]

An average NDVI index value difference was calculated between 2005- and 2014-year periods. Images used were from the active vegetation period, and the differences were used for a cluster analysis representing a statistical technique of determining relatively homogenous pixel groups. Ten pixel group categories were defined that clearly showcase the greatest changes in eastern and central forest areas (Fig. 3) [16].

\subsection{Raster Analysis in Accumulation Dam Areas}

Finally, a limited area raster analysis including just the accumulation dams' areas within the Česma forest was made. The intention was to show the vegetation index change dynamics on vegetated surfaces exclusively. The accumulation dam area analysis revealed vegetation changes in the dam areas. A mask of exclusively forest areas was created. All the images were then masked to enable a spatiotemporal analysis.

Masked images were stacked to calculate the five vegetation indices for each pixel. A recalculation of NDVI, NDWI, GNDVI, EVI and SAVI was done for each masked image in the dam areas. First raw images where the pixel value was defined as a digital number (also known as DN i.e. numerical value describing grey tone value), and then DOS1 (a well-known and described method) atmospherically corrected images were used. Afterward, mean index values in all 92 images along with yearly averages were calculated (Tab. 1).

Table 1 Mean annual vegetation index value [16]

\begin{tabular}{|c|c|c|c|c|c|c|}
\hline Index & Year & $\begin{array}{c}\text { NDVI } \\
\text { DOS1 }\end{array}$ & $\begin{array}{c}\text { NDWI } \\
\text { DOS1 }\end{array}$ & $\begin{array}{c}\text { GNDVI } \\
\text { DOS1 }\end{array}$ & $\begin{array}{c}E V I \\
\text { DOS1 }\end{array}$ & $\begin{array}{c}S A V I \\
D O S 1\end{array}$ \\
\hline 1 & 2005 & 0.6413 & 0.3469 & 0.5285 & 0.7147 & 0.4126 \\
\hline 2 & 2006 & 0.5666 & 0.2530 & 0.4572 & 0.5963 & 0.3435 \\
\hline 3 & 2007 & 0.6617 & 0.1944 & 0.6319 & 0.4069 & 0.3526 \\
\hline 4 & 2008 & 0.5973 & 0.1199 & 0.6059 & 0.3099 & 0.2946 \\
\hline 5 & 2009 & 0.6267 & 0.2632 & 0.6228 & 0.3971 & 0.3555 \\
\hline 6 & 2010 & 0.6225 & 0.2764 & 0.6189 & 0.3952 & 0.3521 \\
\hline 7 & 2011 & 0.6395 & 0.1793 & 0.6237 & 0.4300 & 0.3554 \\
\hline 8 & 2012 & 0.5235 & 0.2805 & 0.4396 & 0.5327 & 0.3211 \\
\hline 9 & 2013 & 0.5792 & 0.2434 & 0.5149 & 0.5118 & 0.3415 \\
\hline 10 & 2014 & 0.5593 & 0.2398 & 0.4857 & 0.4992 & 0.3234 \\
\hline 11 & 2015 & 0.7222 & 0.2357 & 0.7209 & 0.4330 & 0.4068 \\
\hline 12 & 2016 & 0.2687 & 0.1684 & 0.3207 & 0.1461 & 0.1292 \\
\hline
\end{tabular}

Vegetation index results basically demonstrate vegetation cover increase or decrease, depending on annual vegetation shifts. Fig. 4 and Fig. 5 clearly depict vegetation changes and relations in vegetation indices.

Vegetation indices were normalized using annual averages for each image. Values were then stored in table and raster form. A new spatiotemporal mean value indices analysis was made using the newly calculated and normalized indices.
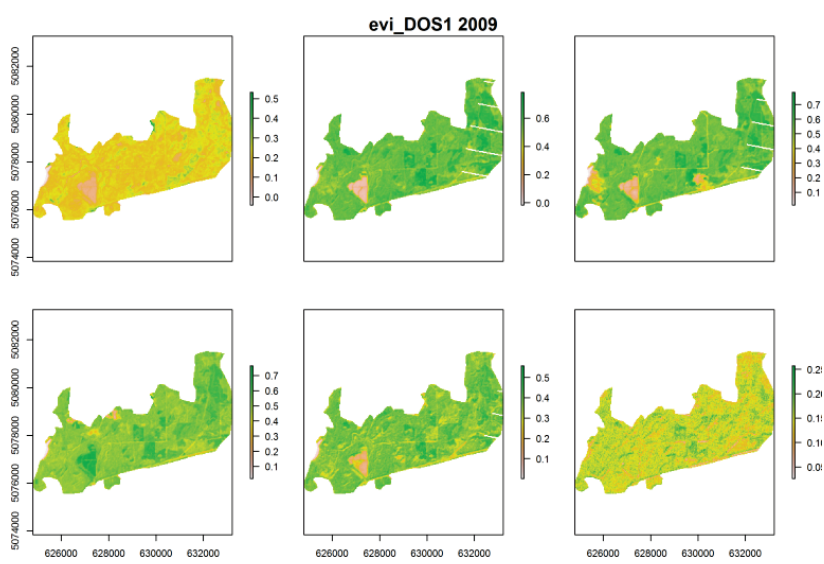

Figure 4 EVI values monthly (December, May, June, July, August and September) distribution for year 2009 [16]

Fig. 4 shows monthly EVI values. The monthly values start from top left corner image in December, followed by EVI results for May, June, July, August and September. Those are also the only Landsat 7 images available for that year, as other have too much cloud cover. The highest index values are in spring for all indices as the highest 
concentration of chlorophyll in plants is in that period, and the same goes for EVI. Fig. 5 shows the NDWI index which indicates water saturation in plants [16].
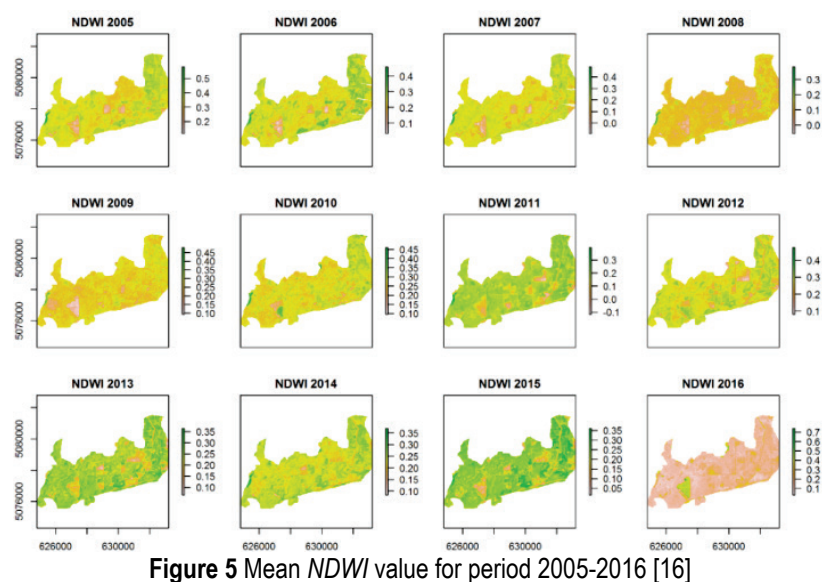

The vegetation index correlation matrix shows a high correlation ratio of indices in thick vegetation areas (Fig. $6)$.

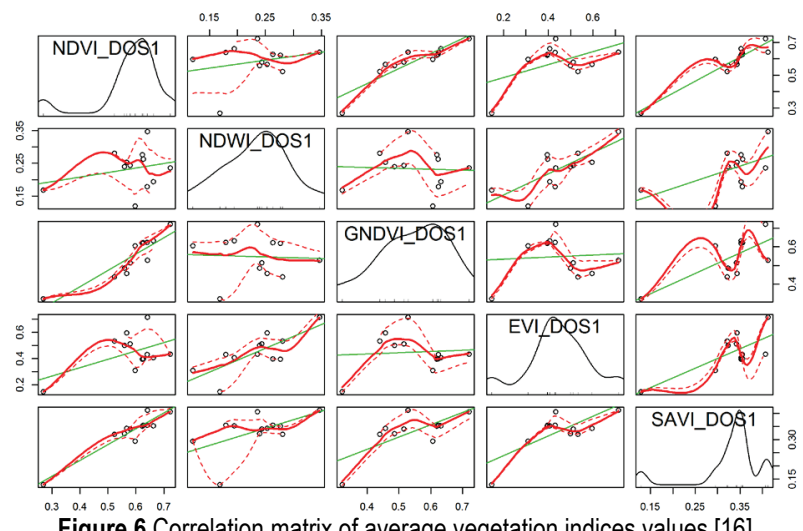

Figure 6 Correlation matrix of average vegetation indices values [16]

A mean vegetation index value was derived from all 92 images, limited to the masked area, and depicted in an annual index trend graph in Fig. 7 (with DOS1 correction) and Fig. 8 (without DOS 1 correction) for all indices combined. The graphs show the same index trends as the ones derived from a point analysis (more in [3]).

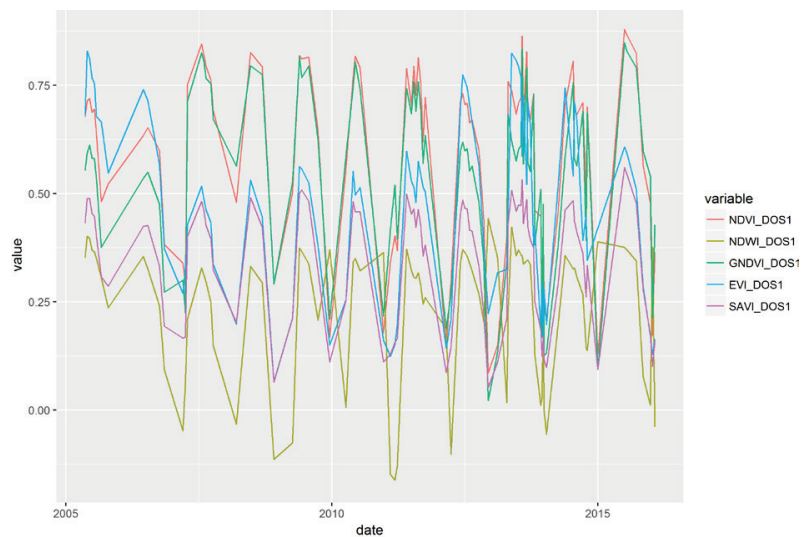

Figure 7 Annual vegetation index trend including DOS1 correction [16]

A Pearson analysis and main component analysis on all indices were made exclusively in the forest area. Pearson linear correlation coefficient shows a positive correlation between indices. Fig. 9 shows correlation of all index pairs in 2015, and diagonally positioned are histograms of each index. A visual inspection confirms that the $E V I$ and $S A V I$ indices are completely correlated when DOS 1 correction is employed $(r=1)$. The greatest correlation in each year was obtained between $E V I$ and $S A V I$, followed by $N D V I$ and GNDVI indices [16].

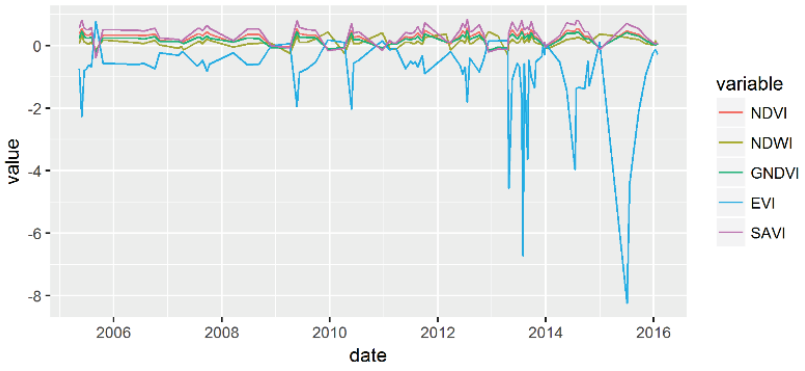

Figure 8 Annual vegetation index trend without DOS1 correction [16]

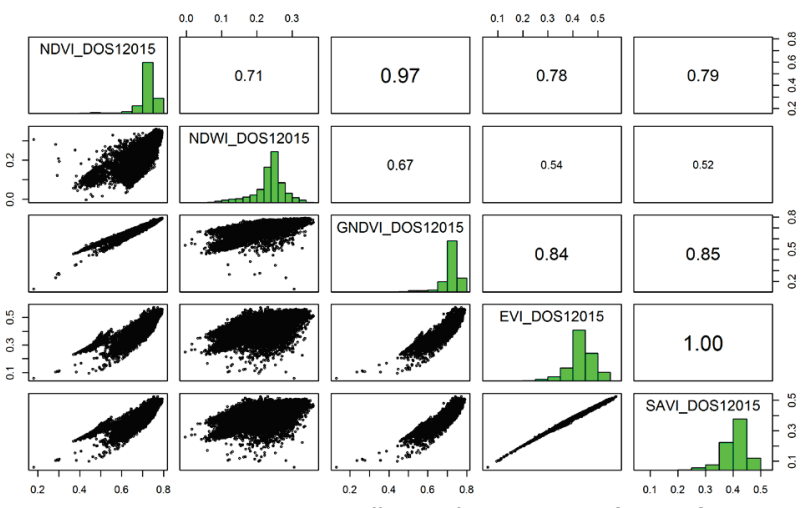

Figure 9 Pearson's correlation coefficient of NDVI, NDWI, GNDVI, SAVI and EVI for 2015 [16]
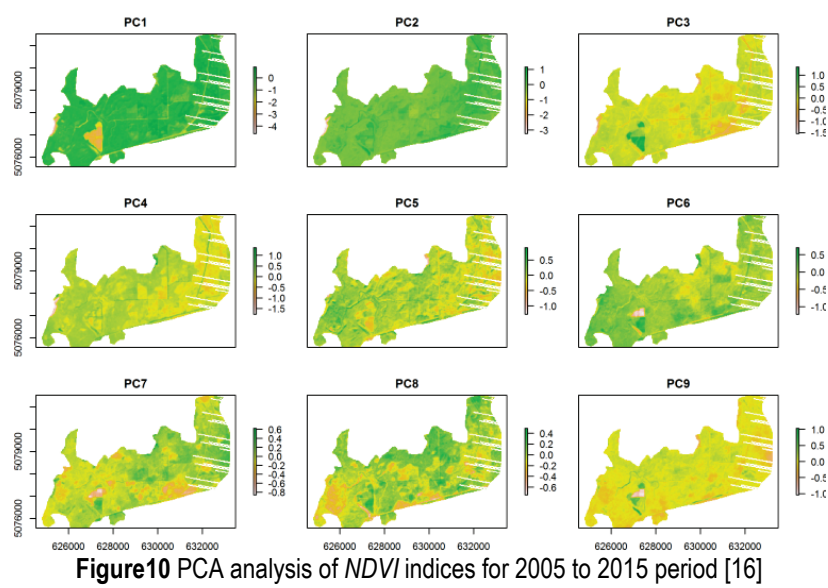

Main components analysis represents one of the simplest multivariant techniques. It is used when there are multiple same dimension variables that lack any additional information compared to those derived from other variables. It makes visual inspection of derived vegetation indices possible, as well as simultaneously obtaining information on all indices and discerning differences in PCA analysis application for each year and index. As the correlation matrix in Fig. 9 shows, indices are correlated which is beneficial to the PCA analysis. Results of PCA analysis on NDVI can be seen in Fig. 10 for the 2005-2015 period. The nine images represent the initial nine components of all NDVI images and depict representative 
changes in forest vegetation cover. The first PCA component represents the main variance trying to describe the original data trend Fig. 10. That variance shows the vegetation amount but also the quality of vegetation changes in the environment [16].

The PCA analysis was conducted for 92 images per index to reduce the number of images to a lesser component number. Fig. 11 shows results of a PCA analysis on one of the indices $(N D W I)$. The characteristics of indices in the entire data set were ultimately downsized to the first nine components [16].

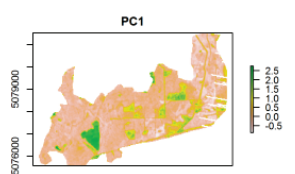

PC4
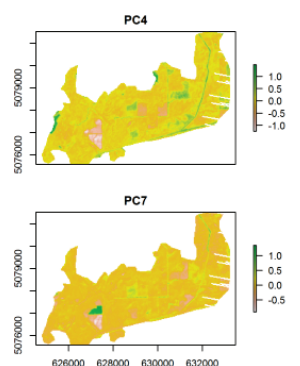

Figure 11 PCA analysis of NDWI indices for 2005 to 2015 period [16]

This was done as it is one approach applied in vegetation index time series analysis that proved appropriate in reducing large data sets and detecting variations in cycle vegetation trends is PCA. Its most valuable characteristic is efficiency in ground-vegetation delineation allowing automatic extraction of forest areas in satellite imagery. It is a fast and less demanding method compared to image classification that requires numerous parameters input. Spatiotemporal vegetation index variances need to be emphasized as long-term changes, where large datasets are grouped into intercorrelated variables.

Results confirm the great potential of PCA remote sensing data analysis in forest cover research.

\section{CONCLUSION}

Vector analysis, index differentiation and pixel grouping were the methods applied to the Česma forest area for change detection aimed at detection and visualization of changes occurring in a select area.

The analysis showed a high correlation between vegetation indices and confirmed the continuity of vegetation trends in all five indices considered in the research. Correlation differences were determined between the indices calculated for a wider and those of the exclusive forest areas. Vegetation indices of forest vegetation areas had double the vegetation index pixel values than those in agricultural areas. The highest correlations were determined in NDVI to GNDVI and SAVI on a wider area, as well as in EVI and SAVI ratios in exclusively forest areas $(0,99-1,00)$, followed by GNDVI and SAVI and similarly $N D V I$ and GNDVI where the correlation was above 0,8 , while $N D W I$ has the lowest correlation ratio in this scenario compared to other indices.
Spatial vegetation index trend is primarily manifested in seasonal vegetation activity. For, when vegetation indices are concerned, the result is biased i.e. dependent on spectral characteristics of the observed object.

Vegetation indices were determined using both the DOS 1 atmospherically corrected and uncorrected satellite imagery.

The research confirmed that EVI is comprised of values not applicable when raw images without atmospheric correction are used (Fig. 8). The same is not the case in the other four indices that can use uncorrected imagery, thus enabling easier processing of large data sets on wider areas.

Unlike younger forests, tree tops of older stands cover greater surface areas and absorb more water which is clearly identifiable in annual NDWI mean values. EVI shows variations in vegetation structure and is a good type of forest stand indicator as well as forest topography visualization asset because it allows easy identification of young forest areas. Vector change analysis is clearest in $E V I$. It clearly identified vegetation changes in accumulation dam areas.

We can conclude that prediction of forest ecosystem development based on detailed spatiotemporal vegetation index analysis is possible.

Data processing was done using open source programs like Saga, Semi-Automatic Classification Plugin for QGIS and statistical programming language $\mathrm{R}$. $\mathrm{R}$ proved to be a valuable resource in processing 92 raster images needed for a quality geostatistical analysis.

Compared to the previous point analysis research [3], we can conclude that the point and raster analysis show matching trends in NDVI, NDWI, GNDVI and SAVI. Value dissipation of all indices in both point and raster analysis shows a slight downward trend of vegetation activity. This proves that spatiotemporal analysis on an entire raster can produce same trend results like those of the point analysis.

It allows change detection, tracking and monitoring on wide areas more promptly than with other methods

Also, comparative advantage of the applied method to point analysis for wide area is that it allows prompt change detection and tracking of vegetation index trends using atmospherically non-corrected imagery.

\section{Acknowledgments}

This research was supported by the Croatian Science Foundation under the projects IP-2016-06-5621 "Geospatial Monitoring of Green Infrastructure by Means of Terrestrial, Airborne and Satellite Imagery (GEMINI)".

\section{REFERENCES}

[1] Miljković, V. (2017). Spatial Calibration of Multispectral and Hyperspectral Sensors in Close-Range Photogrammetry. Doctoral dissertation, PhD Thesis, Faculty of Geodesy, University of Zagreb, Zagreb (in Croatian).

[2] Pernar, R. \& Šelendić, D. (2006). Prilog povećanju interpretabilnosti aerosnimaka i satelitskih snimaka za potrebe uređivanja šuma. Glas. šum. pokuse, pos. izd, 5, 467477.

[3] Vela, E., Medved, I., \& Miljković, V. (2017). Geostatistička analiza vegetacijskih indeksa na šumskom ekosustavu Česma. Geodetski list, 71(1), 25-40. 
[4] Retrieved from http://zeleni-prsten.hr/web/cesma/

[5] Pilaš, I. \& Planinšek, Š. (2011). Obnova vodnog režima nizinskih šuma kao potpora potrajnom gospodarenju. Šumarski list, 135(13), 138-147.

[6] Vrbek, B. \& Pilaš, I. (2000, January). The characteristics of the land covering of Žutica forest. Hrvatski biološki kongres.

[7] Goward, S. N., Masek, J. G., Williams, D. L., Irons, J. R., \& Thompson, R. J. (2001). The Landsat 7 mission: Terrestrial research and applications for the 21st century. Remote Sensing of Environment, 78(1-2), 3-12. https://doi.org/10.1016/S0034-4257(01)00262-0

[8] Knight, E. J. \& Kvaran, G. (2014). Landsat-8 operational land imager design, characterization and performance. Remote Sensing, 6(11), 10286-10305. https://doi.org/10.3390/rs61110286

[9] Liu, J., Chen, J. M., Cihlar, J., \& Park, W. M. (1997). A process-based boreal ecosystem productivity simulator using remote sensing inputs. Remote sensing of environment, 62(2), 158-175. https://doi.org/10.1016/S0034-4257(97)00089-8

[10] Chen, J. M. (1996). Evaluation of vegetation indices and a modified simple ratio for boreal applications. Canadian Journal of Remote Sensing, 22(3), 229-242. https://doi.org/10.1080/07038992.1996.10855178

[11] Myneni, R. B., Keeling, C. D., Tucker, C. J., Asrar, G., \& Nemani, R. R. (1997). Increased plant growth in the northern high latitudes from 1981 to 1991. Nature, 386(6626), 698. https://doi.org/10.1038/386698a0

[12] Wang, F. M., Huang, J. F., Tang, Y. L., \& Wang, X. Z. (2007). New vegetation index and its application in estimating leaf area index of rice. Rice Science, 14(3), 195203. https://doi.org/10.1016/S1672-6308(07)60027-4

[13] Huete, A. R. (1988). A soil-adjusted vegetation index (SAVI). Remote sensing of environment, 25(3), 295-309. https://doi.org/10.1016/0034-4257(88)90106-X

[14] Huete, A., Didan, K., Miura, T., Rodriguez, E. P., Gao, X., \& Ferreira, L. G. (2002). Overview of the radiometric and biophysical performance of the MODIS vegetation indices. Remote sensing of environment, 83(1-2), 195-213. https://doi.org/10.1016/S0034-4257(02)00096-2

[15] Wang, Y., Huang, F., \& Wei, Y. (2013, June). Water body extraction from LANDSAT ETM+ image using MNDWI and KT transformation. Geoinformatics (GEOINFORMATICS), $201321^{\text {st }}$ International Conference on, 1-5. https://doi.org/10.1109/Geoinformatics.2013.6626162

[16] Vela, E. Prostorno-vremenska analiza satelitskih snimki $i$ terestičkih mjerenja šumskih ekosustava. Doktorski rad, Geodetski fakultet Sveučilišta u Zagrebu, Zagreb.

\section{Contact information:}

\section{Ela VELA, PhD}

Hrvatske ceste d.0.0

Metalčeva 5, 10000 Zagreb, Croatia

E-mail: ela.vela@hrvatske-ceste.hr

Vanja MILJKOVIĆ, PhD

(Corresponding author)

Faculty of Geodesy,

Kačićeva 26, 10000 Zagreb, Croatia

E-mail: vmiljkovic@geof.hr

Luka BABIĆ, PhD

Faculty of Geodesy,

Kačićeva 26, 10000 Zagreb, Croatia

E-mail: Ibabic@geof.hr 